\title{
Clinical ethics committees: a worldwide development
}

Anne Slowther, Tony Hope and Richard Ashcroft University of Oxford and Imperial College, London

Clinical ethics committees (CECs) are well established in North America where they are known as hospital or health care ethics committees. Similar groups and other kinds of clinical ethics support are now developing in Europe. This supplement to the Fournal of Medical Ethics provides an overview of the issues arising from the provision of clinical ethics support services, and clinical ethics committees in particular. Its primary focus is the UK but contributors from North America and continental Europe provide an international perspective.

Clinical ethics committees are an emerging feature of UK health care. This supplement's first paper provides an overview of the current provision of clinical ethics support in the UK and an assessment of the way in which CECs are developing. Personal perspectives from five UK CECs provide insight into some of the issues that those considering setting up a committee in their own trust will need to address.

In Germany CECs are at a similar stage of development to the UK. However, a "top down" impetus, as in the committee described by Simon, is more common than in the UK. Simon describes the work of a CEC in case consultation. A different model of case consultation using individual ethicists is described by Reiter-Theil.

Danis and colleagues have found that requests for ethics case consultations, either to a committee or an ethicist, are more likely to be triggered by conflict than by cognitively based concerns. They conclude that those involved in ethics consultation will need skills in mediation as well as ethical analysis.

Should ethics case consultation be by committee or individual ethicist? A committee has the advantage of bringing a broader range of views and expertise to the ethical problems, but an individual ethicist can be more responsive to a request for an urgent consultation. Eiser and colleagues describe ways in which some advantages of both methods can be combined by using electronic communication between CEC members to facilitate case consultation in two hospitals in Chicago. Electronic communication is already having an effect on clinical medicine and is likely to have implications for ethics support services. Parker and Gray discuss some of these wider issues in their paper on e-ethics.
In the Netherlands CECs (known as institutional ethics committees) are more widespread than in the UK. Meijburg and ter Meulen have been involved in developing and training such committees for several years and their paper provides advice for health care institutions considering establishing a CEC. The wider issue of educating all health professionals within the institution is discussed by Tweeddale in his account of his experience as a member of a CEC in Vancouver.

Doyal considers the role of a CECs as a forum for collective debate in order to provide coherent ethicolegal institutional policies. Any CEC influencing institutional policy or clinical care will need to be aware of legal as well as ethical principles and will need to ensure that its constitution and procedures stand up to legal scrutiny. These issues are discussed more fully by Hendrick.

The position of CECs in the context of clinical governance is discussed by Campbell, who argues that CECs have the potential to improve the quality of clinical care within the NHS.

This supplement provides a firm reference point from which to consider the future development of clinical ethics support services in the UK. There is evidence of demand for such a service, but there is also experience of the limitations that such a service can face. Do CECs, or other ethics support services, deliver the support that clinicians and institutions need, when they need it, and of appropriate quality? Do they, in short, promote the quality of health care? The promise of CECs is clear, and the experience recorded in this supplement of the journal makes us optimistic for their future. It remains now to be seen whether CECs can make good this early promise.

Anne Slowther, MRCGP, MA, is an NHS RED Primary Care Research Training Fellow at the Oxford Centre for Ethics and Communication in Health Care Practice (Ethox). Tony Hope, PhD, FRCPsych, is Director of Ethox and Professor of Medical Ethics, Division of Public Health and Primary Care, University of Oxford. Richard Ashcroft, MA, PhD, is Sir Siegmund Warburg Lecturer in Medical Ethics, Medical Ethics Unit, Department of Primary Health Care and General Practice, Imperial College, London. 